\title{
Simulation of aerosol dispersion during medical examinations
}

\author{
Sebastian Falk \\ Division of Phoniatrics and Pediatric Audiology \\ Friedrich-Alexander-University Erlangen-Nürnberg \\ Erlangen, Bavaria, 91054 \\ Germany \\ Email: sebastian.falk@uk-erlangen.de
}

\author{
Sarina K Mueller \\ Department of Otorhinolaryngology Head \& Neck Surgery \\ University Hospital Erlangen, Medical School \\ Erlangen, Bavaria, 91054 \\ Germany
}

Stefan Kniesburges

Division of Phoniatrics and Pediatric Audiology

Friedrich-Alexander-University Erlangen-Nürnberg

Erlangen, Bavaria, 91054

Germany

Michael Döllinger

Division of Phoniatrics and Pediatric Audiology

Friedrich-Alexander-University Erlangen-Nürnberg

Erlangen, Bavaria, 91054

Germany

\begin{abstract}
The main route of transmission of the SARS-CoV2 virus has been shown to be airborne. The objective of this study is to analyze the aerosol dispersion and potential exposure to medical staff within a typical medical examination room during classical airway procedures. The multiphase simulation of the aerosol particles in the airflow is based on a Lagrangian-Eulerian approach. All simulation cases with surgical mask show partially but significantly reduced maximum dispersion distances of the aerosol particles compared to the cases without surgical mask. The simulations have shown that medical examiner are exposed to large amount of aerosol particles, especially during procedures such as laryngoscopy where the examiner's head is directly in front of the the patient's face. However, exposure can be drastically reduced if the patient wears a mask which is possible for the most of the procedures studied, such as otoscopy, sonography, or anamnesis.
\end{abstract}

\section{Introduction}

Coronavirus disease 2019 (COVID-19) is an acute respiratory illness caused by the SARS-CoV-2 (Severe Acute Respiratory Syndrome Coronavirus 2) coronavirus. The socioeconomic impact cannot be compared to any other pandemic before [1]. SARS-CoV-2 results in high variability of symptoms. While some patients have mild symptoms of upper respiratory tract infection, others suffer severe sequelae resembling acute respiratory distress syndrome (ARDS) [2-4].

The main route of transmission of the SARS-CoV2 virus has been shown to be airborne by hoovering aerosol particles. To date, at least 115,000 healthcare workers have died from SARS-CoV2 [5]. Owing to the high exposure of aerosol particles during clinical airway procedures $[6,7]$. Thus, for their own safety, but also for the maintenance of healthcare and the safety of the rest of the population, it is of great importance to minimize the exposure of clinical staff. Several recommendations to ensure maximum safety of medical personnel during airway management procedures are developed and updated regularly [6-11]. This includes limiting some pro- 
cedures to the minimum necessary, including bronchoscopy or tracheal cannula change in SARS-CoV2-positive patients.

Looking at the receiver, inhalable aerosol particles must contain particles or liquid droplets smaller than $\approx 20 \mu \mathrm{m}$. However, only particles with a diameter $<5 \mu m$ (fine particles) can effectively penetrate the lower parts of the respiratory tract, e.g., the small bronchi and alveoli [12]. There are different definitions of airborne transmission of pathogens by liquid aerosol particles. Some authors use the terms droplets for objects larger than $20 \mu \mathrm{m}$ and droplet nuclei for objects smaller than $5 \mu m[4,8,13,14]$. Other authors distinguish between liquid particles suspended in the air that remain in the air for a short time due to ballistic trajectories (droplets) and particles that float and remain in the air for a longer time (aerosol particles). In this study, based on previous results of our group (clinical characterization), we will use the second definition based on ballistic and hovering behavior of respiratory particles [15]. Filtering mechanisms in the upper airways effectively seems to remove the majority of particles larger than $5 \mu \mathrm{m}$ from the air stream already in the nose/mouth/throat [12]. After passing through the upper airway filters, aerosol particles enter the bronchial tree more slowly. Particles that do not settle during inhalation may also be retained in the airways during exhalation [12]. In this context, it is important to emphasize that aerosol particles from the bronchial tree/alveoli can increase their size in the airways and be delivered as droplets on exhalation. Ultrafine particles $(<100 \mathrm{~nm})$ have a high probability of deposition to the bronchial tree and alveoli. However, they are not considered because coronavirus, an enveloped virus with a size of $120-160 \mathrm{~nm}$, is larger than ultrafine aerosol particles and were found to be clinically insignificant $[4,12,16]$. Exhaled aerosol particles that are between 0.1 and $0.5 \mu \mathrm{m}$ in size may potentially contain at least one virostatic agent $[4,12,16]$.

A prerequisite for infection is that the virus remains infectious and replicable in these small particles [14]. Previous studies have shown that the SARS-CoV2 virus can remain airborne for several hours [17]. However, the airborne residence time depends on size and trajectory, among other factors. The aerosol production rate varies greatly from person to person. While breathing rate has been shown to have no effect on aerosol concentration, inhalation of surfactant or isotonic $\mathrm{NaCl}$ results in significant changes. Inhalation of surfactant increased the aerosol concentration by $300 \%$. Inhalation of isotonic $\mathrm{NaCl}$, on the other hand, was able to reduce particle exhalation by $<70 \%$ [18]. A study by [19] also indicated that patients with respiratory infections produce more aerosol particles (especially at $1 \mu \mathrm{m}$ ) than healthy individuals $[11,19,20]$. While gender was not a major influence in previous studies, the product of age and body mass index (BMI) turned out to be a good predictor of aerosol production with a critical threshold for increased aerosol production of 650 and larger [21].

Numerous studies on the fluid dynamics of droplets and aerosol particles have been conducted in recent years, particularly in the context of the COVID-19 pandemic.
Experimental studies focusing on the behavior of cough flow at greater distances from the mouth [22] or on the droplets and aerosol particles during normal speech [23] were done.

Numerical studies on the effect of wind speed on social distancing [24], of high flow oxygen therapy [25], and of droplet behavior at various relative humidities were performed [13]. Several other studies (e.g., [26-29]) and international online conferences $[30,31]$ demonstrate the usefulness and importance of computational fluid dynamic (CFD) simulations for the current COVID-19 pandemic.

An experimental study using particle image velocimetry and hot-wire anemometry was conducted in combination with CFD simulations [22]. In situ measurements and numerical simulations were combined and focused on exhaled aerosol particles under normal respiratory behavior and their transport in an elevator and in small classrooms [32]

Investigations of droplet or aerosol dispersion during normal speech [23,33], coughing [33,34], or breathing [33] were done.

The effects of using a type 1 surgical mask over a patient's face on particle behavior [25] and that masks were able to protect individuals in the environment during breathing, speaking, singing, coughing, and sneezing [33] were studied.

However, these data were not collected under real conditions during airway management procedures with patients. The bulk of the described studies did not deeply investigate airway management procedures.

Thus, it is the aim of this study to analyze the aerosol dispersion and potential exposure to medical staff within a typical medical examination room during classical airway procedures. Detailed knowledge of the size, velocity, trajectories, and flow patterns of various upper and lower airway management procedures is essential for developing effective strategies to reduce the exposure of aerosol particles for medical personnel. Currently, there is no study and no quantitative real-life data.

\section{Methods}

The simulations were performed with Simcenter STARCCM+ 2020.2 CFD solver (Siemens, PLM Software, Plano, TX, USA) based on a Lagrangian Euler approach to model the multiphase flow of the aerosol dispersion [35]. The model uses a combination of an Eulerian segregated solver for the continuous phase in conjunction with a Lagrangian multiphase model for the dispersed phase [35]. The Eulerian-Lagrangian approach exhibited good agreement to experimental data as shown in [36].

Furthermore, the Lagrangian-Eulerian model additionally considers heat and mass transfer phenomena [37]. Coupling between the two phases occurs by mass, momentum, and energy transfer [37]. In the study, one-way coupling was used, where only the continuous phase affects the dispersed phase as exclusively small particles were examined which follow the convectional flow in a slip-free environment having a Stokes number $(\mathrm{St})$ much lower than one 
Table 1. The paradigm in combination with their inlet profiles, which were performed in this study. A total of 16 simulation cases for eight paradigm (with and without surgical mask) were simulated.

\begin{tabular}{|c|c|c|c|}
\hline Case & Paradigm & $\begin{array}{l}\text { Position: Patient } \\
\text { and Examiner }\end{array}$ & $\begin{array}{l}\text { Inlet } \\
\text { profile }\end{array}$ \\
\hline 1 & Anamnesis & $\begin{array}{l}\text { sitting / } \\
\text { standing in distance }\end{array}$ & Speaking \\
\hline 2 & Laryngoscopy & $\begin{array}{l}\text { sitting / } \\
\text { standing in front }\end{array}$ & Breathing \\
\hline 3 & Laryngoscopy & $\begin{array}{l}\text { sitting / } \\
\text { standing in front }\end{array}$ & Coughing \\
\hline 4 & Otoscopy & $\begin{array}{l}\text { sitting / } \\
\text { standing besides }\end{array}$ & Breathing \\
\hline 5 & Otoscopy & $\begin{array}{l}\text { sitting / } \\
\text { standing besides }\end{array}$ & Speaking \\
\hline 6 & Rhinoscopy & $\begin{array}{l}\text { sitting / } \\
\text { standing in front }\end{array}$ & Sneezing \\
\hline 7 & Sonography & $\begin{array}{l}\text { lying / } \\
\text { sitting besides }\end{array}$ & Breathing \\
\hline 8 & Sonography & $\begin{array}{l}\text { lying / } \\
\text { sitting besides }\end{array}$ & Speaking \\
\hline
\end{tabular}

$(\mathrm{St}<<1)$ [38].

For modeling turbulence, the unsteady Reynoldsaveraged Navier-Stokes model (unsteady RANS) is used with the well-established and widely used SST (Menter) KOmega model [39].

A constant density is assumed for the continuous and dispersed phases. The airflow in the continuous phase has a density of $\rho_{\text {air }}=1.2041\left[\frac{\mathrm{kg}}{\mathrm{m}^{3}}\right]$, and a dynamic viscosity of $\mu_{\text {air }}=1.82 E-5\left[\frac{\mathrm{Pa}}{\mathrm{s}}\right]$ ), and the aerosol particles of the dispersed phase are defined as liquid particles with the properties of water/slime with a density of $\rho_{\text {aerosols }}=997.6\left[\frac{\mathrm{kg}}{\mathrm{m}^{3}}\right]$ [40].

In order to track the aerosol behavior over a sufficiently long and appropriate time period in the numerical domain, a physical time of $60 \mathrm{~s}$ is simulated. A second-order upwind scheme is used to discretize the convective and diffusive terms of the Navier-Stokes equations [41]. The implicit method is used for this transient simulation. Time step sizes of $10^{-3} \mathrm{~s}$ for the physical time of $0 \mathrm{~s}<t \leq 10 \mathrm{~s}$ and of $10^{-2} \mathrm{~s}$ for $10 \mathrm{~s}<t \leq 60 \mathrm{~s}$ are used [25,42-44]. An algebraic multigrid method with a Gauss-Seidel relaxation scheme is used to solve the final linear system of partial differential equations.

\subsection{Simulation cases}

The eight cases of the five paradigm (anamnesis, laryngoscopy, otoscopy, rhinoscopy, and sonography) in combination with the three inlet profiles (speaking, breathing, and coughing), see table 1, with and without a surgical mask are simulated for a physical time of $60 \mathrm{~s}$. The paradigm mainly define the position of the medical examiner in relation to the patient. Overall 16 simulation cases were executed.
From the simulations, the following parameters are calculated for different aerosol sizes: Dispersion of aerosol particles near the investigator's head and the extent in all three spatial directions. The values are compared descriptively between the simulation cases.

\subsection{Numerical domain}

The numerical domain of the examination room consists of a rectangular room with a floor plan of $3.0 \times 4.5 \mathrm{~m}$ and a ceiling height of $2.5 \mathrm{~m}$, see Fig. 1. The patient sits on a treatment chair or lies on a treatment couch depending on the respective paradigm, see table 1 . The medical examiner is placed in front or at the side of the patient, see Fig. 1.

\subsection{Boundary conditions}

All surfaces including walls, persons and furniture are defined as non-moving impermeable walls, see Fig. 1. The surgical masks were considered as impermeable rebound walls. The patient's mouth is defined as mass (speaking and breathing) or velocity (coughing) inlet for the airflow of the continuous phase. For the rhinoscopy the inlet is the nose (sneezing).

There is no initial velocity of the environmental air in the examination room. However, the flow fields of the continuous phase are initialized by simulating $60 \mathrm{~s}$ physical time using the respective profile inlets. The flow velocity during the experimental procedures ranges in the low Reynolds number $(\operatorname{Re}<1000)$ region with the kinematic viscosity of air $\mathrm{v}_{\text {air }}=1.516 E-5 \frac{\mathrm{m}^{2}}{\mathrm{~s}}$ at $T=20^{\circ}[45]$.

\section{Profiles of the inlet boundaries (continuous phase)}

The realistic coughing velocity profile of Gupta et al. [46] is scaled to the maximum total velocity of $26.4 \frac{\mathrm{m}}{\mathrm{s}}$ taken from the experiments of Müller et al. [15], see Fig. 2 . This cough profile is then used for the paradigm with coughing and sneezing for rhinoscopy. The breath volume flow profile, defined as mass flow, is taken from Tabuenca Javier Garcia [47], see Fig. 2. Continuous speech was defined by a mass flow of $0.28 \frac{\mathrm{g}}{\mathrm{s}}$ [48].

For the mesh independence study an polyhedral grid with an adaptive meshing strategy was used, see Fig. 3. Similar to Pendar and Páscoa [34], an inlet velocity at the patient's mouth (inlet boundary) was specified time-dependently on the basis of the cough profile. Five different meshes (MB M4) with an increasing spatial resolution (1.99-10.30 million elements) were created. Mesh M2 with a tolerable deviation of the velocity at measuring point $\mathrm{P} 1$ at a distance of $0.1 \mathrm{~m}$ from the inlet and a calculation time kept within limits was selected, see table 2 .

\subsection{Particle distribution and injection (dispersed phase)}

Experimental measurements are used as input for the injected aerosol particles in the simulation cases. The particle distributions during breathing, coughing, and speaking are based on experimental measurements with an Optical Particle Sizer (OPS) (Model 3330, TSI Incorporated, Shoreview, 
bioRxiv preprint doi: https://doi.org/10.1101/2021.11.22.469529; this version posted November 23, 2021. The copyright holder for this preprint (which was not certified by peer review) is the author/funder. All rights reserved. No reuse allowed without permission.
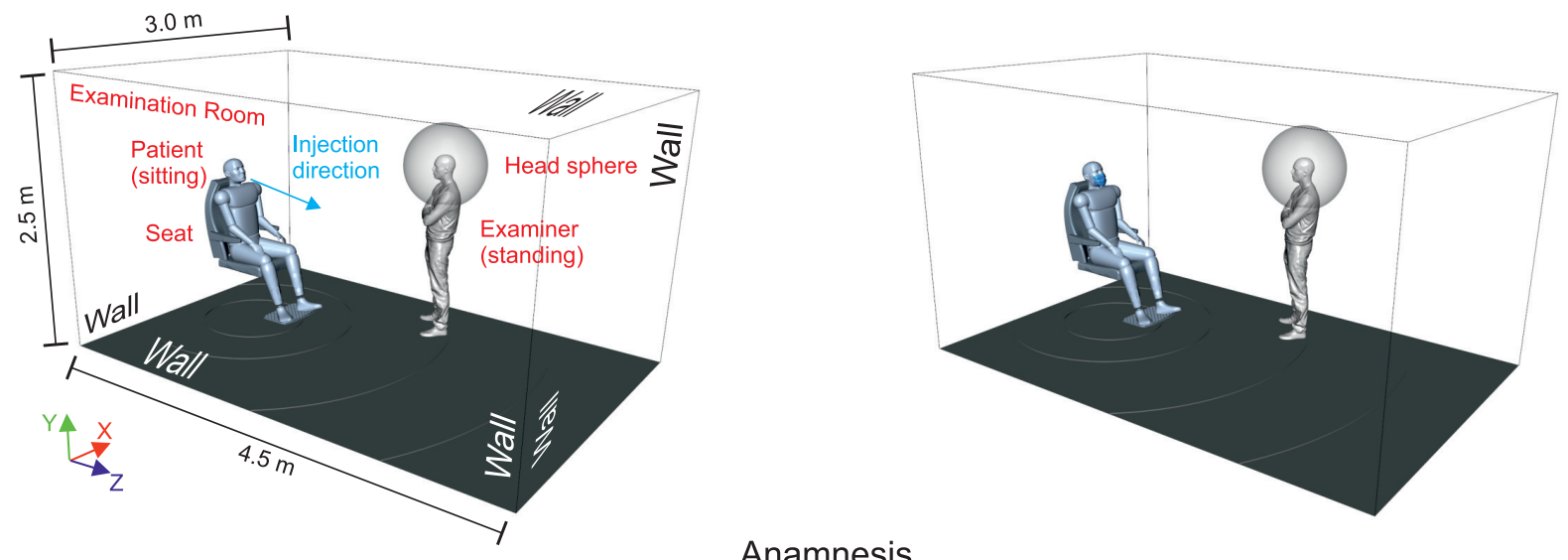

Anamnesis
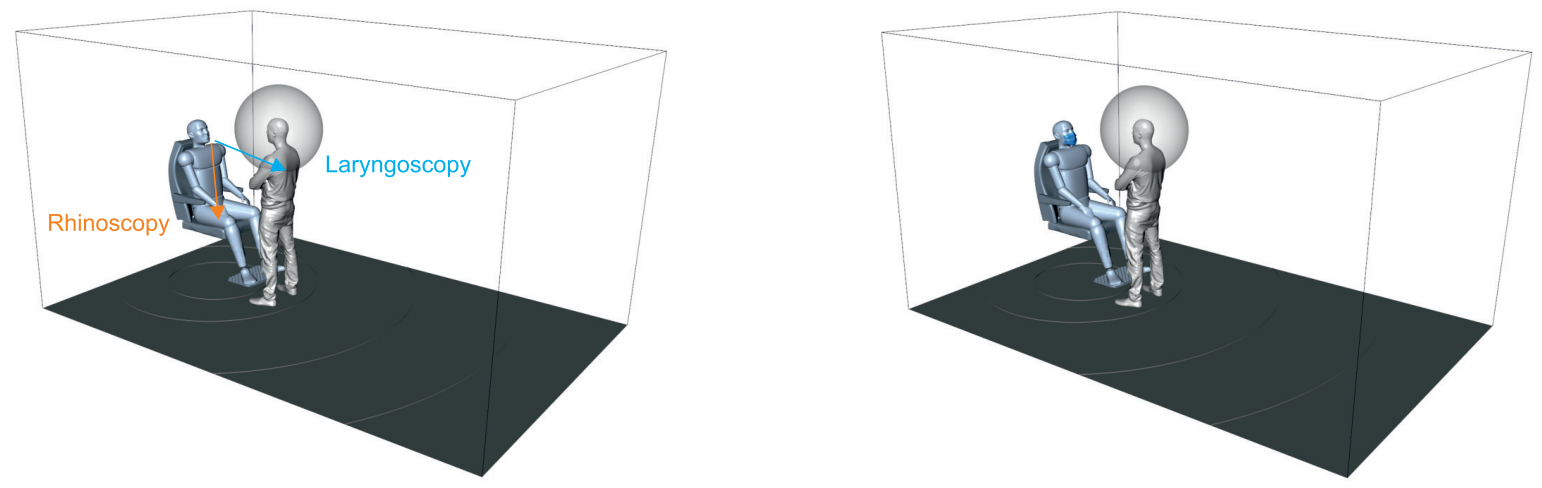

Laryngoscopy and rhinoscopy
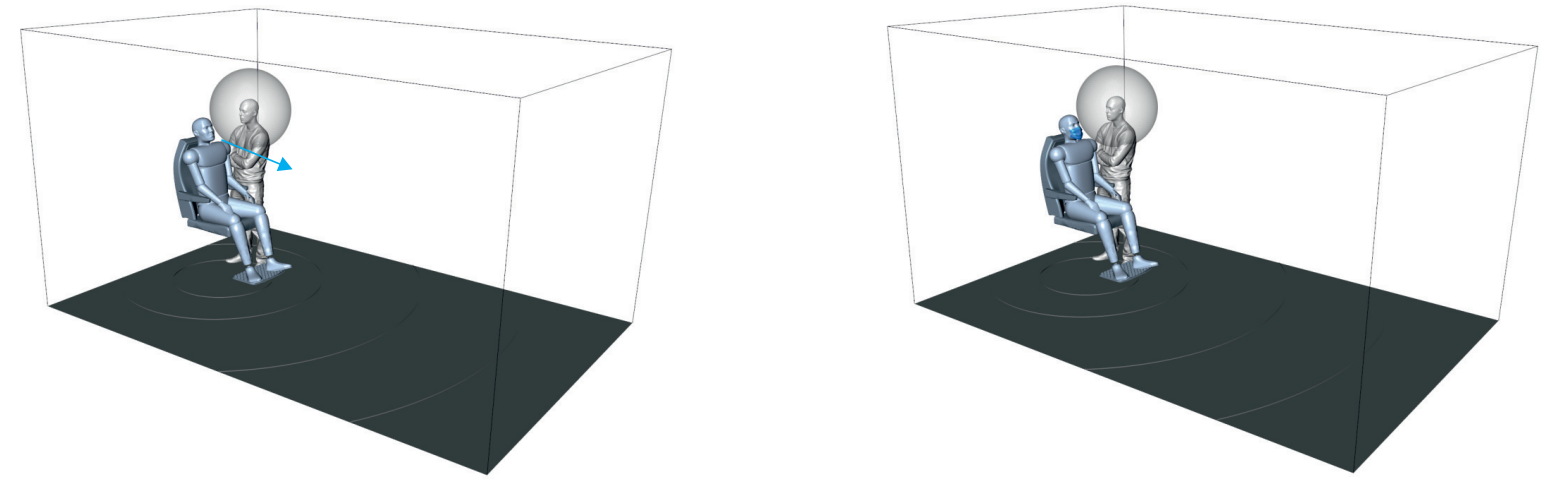

\section{Otoscopy}

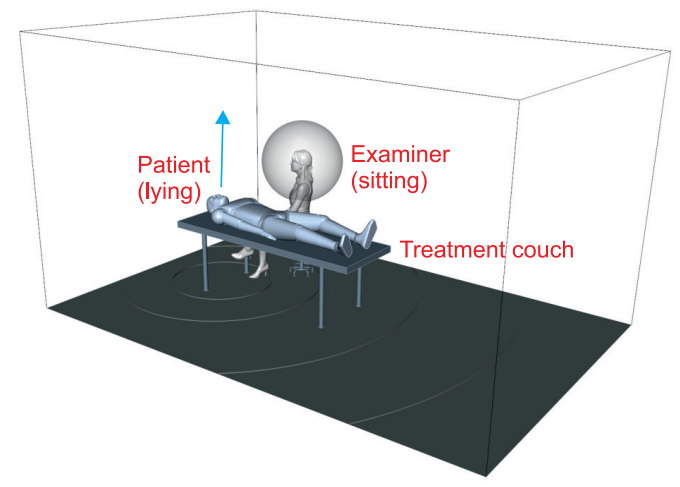

with mask

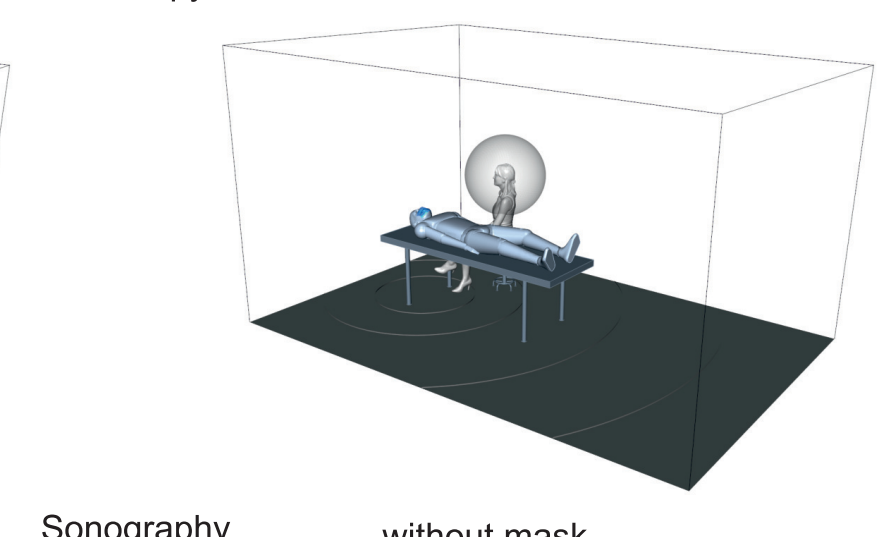

Fig. 1. General geometry of the numerical examination room of all simulation cases and the positions of the patient and the examiner within it. The head spheres are positioned around the examiners' heads with a diameter of $0.8 \mathrm{~m}$ and their surfaces track the incoming aerosol particles. 
bioRxiv preprint doi: https://doi.org/10.1101/2021.11.22.469529; this version posted November 23, 2021. The copyright holder for this preprint (which was not certified by peer review) is the author/funder. All rights reserved. No reuse allowed without permission.

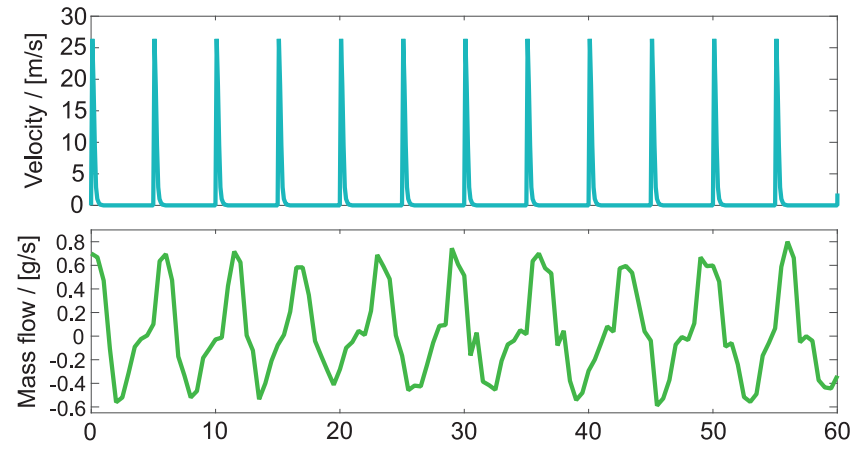

Fig. 2. Profiles of coughing/sneezing (upper part) and breathing (lower part) for $60 \mathrm{~s}$.

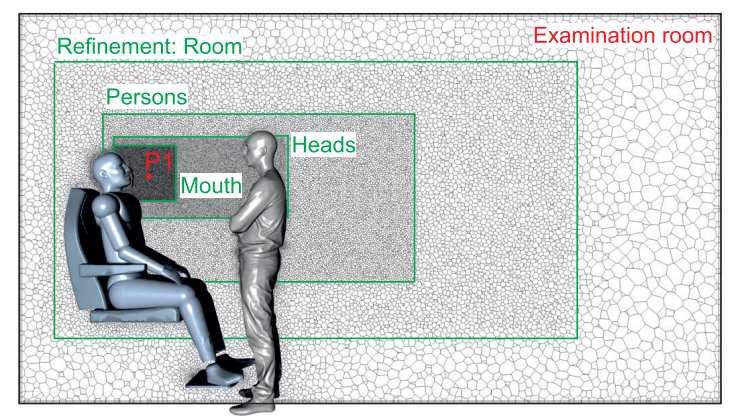

Fig. 3. Grid within the numerical examination room with the four refinements steps and the velocity measuring point $\mathrm{P} 1$.

Table 2. Properties of mesh M2 of the grid independence study. The velocity at measuring point $\mathrm{P} 1$ is given as relative deviation to mesh MB.

\begin{tabular}{lcccc}
\hline Mesh & $\begin{array}{c}\text { Basic } \\
\text { cell } \\
\text { size }\end{array}$ & $\begin{array}{c}\text { No. of } \\
\text { cells }\end{array}$ & $\begin{array}{c}\text { Computing } \\
\text { time }\end{array}$ & $\begin{array}{c}\text { Rel. dev. } \\
\text { of velocity } \\
\text { at P1 }\end{array}$ \\
\hline M2 & 0.05 & 6.3 Mio. & $31.0 \mathrm{~h}$ & $-3.6 \%$ \\
\hline
\end{tabular}

Minnesota, USA). The OPS divides the measuring range into so-called size buckets.

Based on the measurements, Fig. 4 shows the relative number of aerosol particles distribution for breathing, speaking and coughing for the OPS buckets. For each bucket, the mean value of the specific range and the percentage of aerosol particles are given. For breathing, the OPS detected aerosol particles only in the first 5 buckets, for speaking in the first 10 buckets, and for coughing in 12 buckets. These size distributions were similarly reported in the literature [49].

At the inlet boundary, an injector is placed which feeds the aerosol particles with size distribution from Fig. 4 into the simulation region.

The inject axes, see Fig. 1, are along:

- the z-axis for anamnesis, laryngoscopy, and otoscopy,

- the y-axis in positive direction for sonography,
A

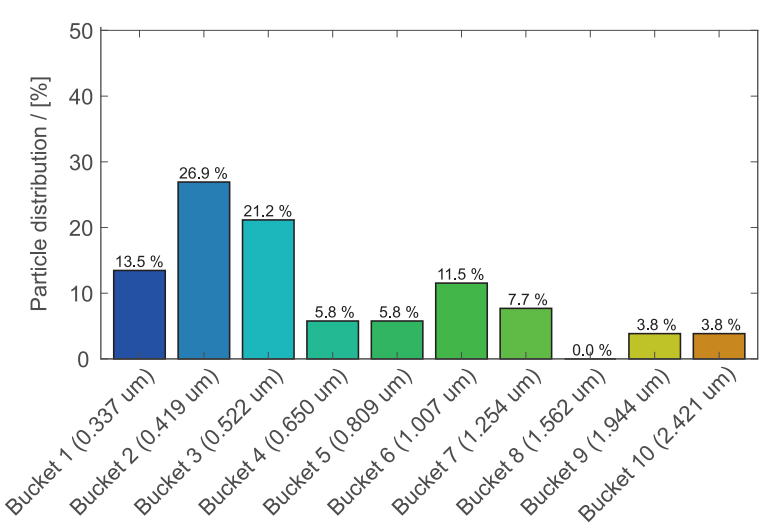

B

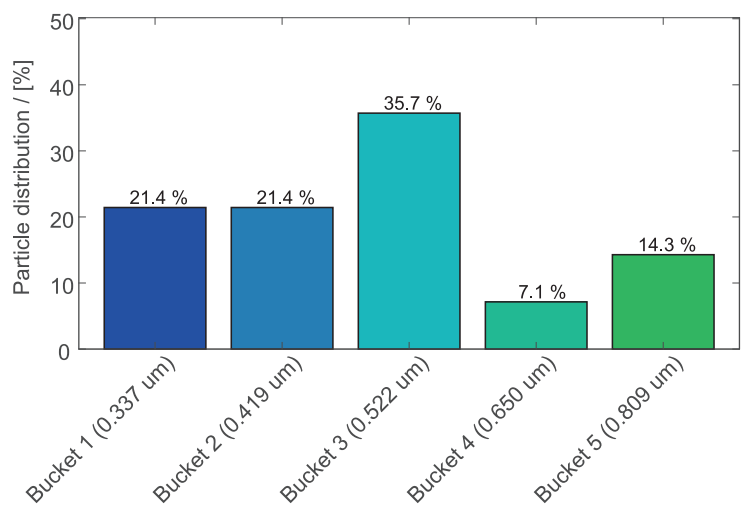

C

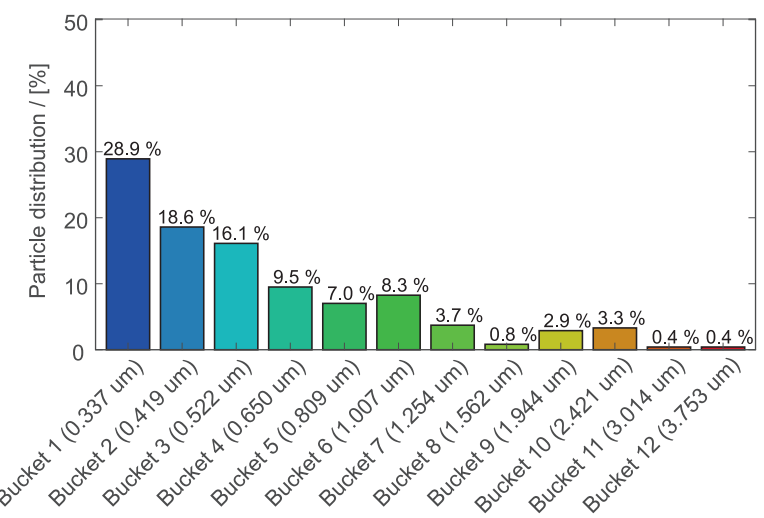

Fig. 4. Percentage particle distribution of (A) breathing, (B) speaking, and (C) coughing among the buckets of the OPS.

- the y-axis in negative direction for rhinoscopy.

The injector forms a cone-shaped spreading characteristic with a inclination angle of $60^{\circ}$. The aerosol particles are injected with an initial velocity of $0 \frac{m}{s}$ and subsequently captured by the inlet flow which is not decelerated by the particles.

\section{Results}

\subsection{Dispersion of aerosol particles on the examiners head sphere}

To count the particles that enter the near field of the examiner's head, we created so-called head spheres around the examiner's head. Figure 1 shows for each simulation configuration the head spheres of diameter $0.8 \mathrm{~m}$ around the examiners' heads. Aerosol particles that cross the head spheres 
Table 3. Percentage of the total number of particles fed into the numerical domain of the 16 simulation cases that were detected by the examiners' head spheres.

\begin{tabular}{llcc}
\hline Case & Paradgim/Profile & $\begin{array}{c}\text { with } \\
\text { surgical } \\
\text { mask }\end{array}$ & $\begin{array}{c}\text { without } \\
\text { surgical } \\
\text { mask }\end{array}$ \\
\hline 1 & Anamnese/Speaking & $0.0 \%$ & $0.0 \%$ \\
2 & Laryngoscopy/Breathing & $0.0 \%$ & $55.0 \%$ \\
3 & Laryngoscopy/Coughing & $0.0 \%$ & $64.0 \%$ \\
4 & Otoscopy/Breathing & $0.03 \%$ & $0.0 \%$ \\
5 & Otoscopy/Speaking & $0.0 \%$ & $0.0 \%$ \\
6 & Rhinoscopy/Sneezing & $0.0 \%$ & $0.0 \%$ \\
7 & Sonography/Breathing & $0.0 \%$ & $0.0 \%$ \\
8 & Sonography/Speaking & $0.0 \%$ & $0.0 \%$ \\
\hline
\end{tabular}

were tracked and counted.

Table 3 shows that the head spheres of the cases laryngoscopy with breathing and coughing, each without surgical mask, registered an enormous amount of aerosol particles with $55.0 \%$ and $64.0 \%$ of the total number of aerosol particles emitted by the patient. The head sphere of otoscopy breathing with surgical mask counted a relatively small number of aerosol particles of about $0.03 \%$.

Figure 5 shows the size distribution for the three simulation cases that registered aerosol particles at the examiners' head spheres. The largest percentage of the tracked aerosol particles occurs with low diameter particles.

\subsection{Dispersion of aerosol particles in the examination room}

Figure 6 shows the maximum dispersion in all three spatial directions of the aerosol particles in the examination room. Additionally, see supplement videos for the dispersion of the aerosol particles in the examination room over time. All simulation cases with surgical mask show partially but significantly reduced maximum dispersion distances of the aerosol particles compared to the cases without surgical mask.

The main direction without mask is the $\mathrm{z}$-direction which is the main direction of ejection except of the case sonography where the patient lies on a couch and ejects upward in y-direction. Using a mask deflects the aerosol particles in orthogonal directions to the main ejection direction. For otoscopy, these are the positive and negativ $\mathrm{x}$ - and $\mathrm{y}-$ directions. In sonography, the particles are deflected in positive and negative $\mathrm{z}$ - instead of $\mathrm{y}$-directions by the mask. For rhinoscopy sneezing the main ejection is forward-downward directed as shown in supplement video V11.

Figure 7 shows the maximum travel distance (length of the vector from the injector to the material particle) reached by the aerosol particles within a physical time of $60 \mathrm{~s}$ in the numerical domain. It can be clearly seen that the maximum travel distance of aerosol particles with larger size $(\geq 2.241 \mu \mathrm{m})$ decreases with an increasing particle diameter. Furthermore, all simulation cases with surgical mask show a significantly reduced maximum travel distance of the aerosol particles among all buckets.

\section{Discussions}

The large amount of aerosol particles delivered to the near field of the examiner's head in the cases laryngoscopy with breathing and coughing is a consequence of the examiner's position in a short distance in front of the patient's face. The more the examiner is positioned within the patient's exhalation flow region, the more aerosol particles will reach the near field of the examiner especially for coughing. The reason for the detected aerosol particles during otoscopy breathing with surgical mask is, that the exhaling flow is redirected by the surgical mask in lateral direction, so that a small amount of aerosol particles are carried by the flow and were able to enter the head sphere of the examiner, see Fig. 1. This deflection of aerosol particles by different types of masks was multiply observed in experiments [50-52].

The main direction without mask is the exhalation direction for all paradigms and profiles. After a physical time of $60 \mathrm{~s}$, no significant difference in the maximum aerosol dispersion between coughing, breathing and speaking were observed. The maximum travel distance of the aerosol particles in the exhalation direction is significantly reduced by wearing a surgical mask. In addition, larger aerosol particles $(\geq 2.241 \mu \mathrm{m})$ appear to travel less distance compared to smaller aerosol particles.

\section{Conclusions}

The simulations showed that medical examiner are exposed to large amount of aerosol particles especially for interventions as laryngoscopy where the examiner's head is immediately in front of the the patient's face. However, the exposition can be drastically reduced if the patient wears a mask which is in principle possible for the most investigated interventions as otoscopy, sonography or anamnesis. Even for rhinoscopy, the patients should be able to wear a mask. Unfortunately, wearing a mask by the patient is hardly an option for laryngoscopy as the examiner has to position the laryngoscope safely in the oral cavity without irritating the pharyngeal region, which would force coughing or even vomiting. In fact, these two effects often occur during laryngoscopy.

As a consequence of these findings, the examiner should be outside the patient's exhaled air stream, regardless of whether the patient is coughing, speaking, or breathing. Not directly examined in this study, but still worth mentioning, is the importance of the position of additional assistant personnel in the room. Their position should be outside the maximum aerosol trajectory. A effective technique to further reduce the exposure, laminar flow top-to-bottom ventila- 

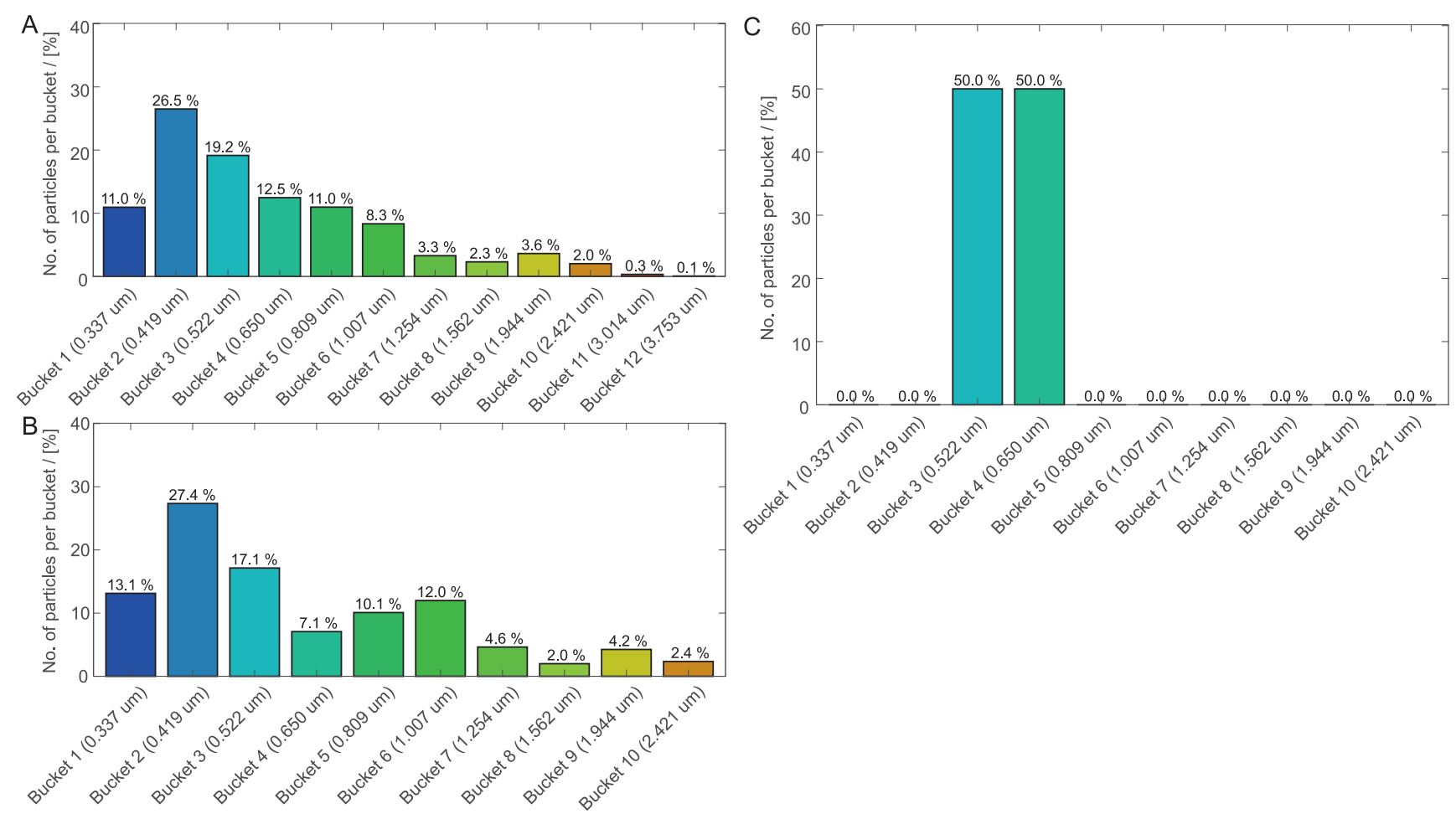

Fig. 5. Distribution of aerosol particles entering the examiner's head sphere by size for (A) laryngoscopy/without surgical mask/coughing, (B) laryngoscopy/without surgical mask/breathing, and (C) otoscopy/with surgical mask/breathing.

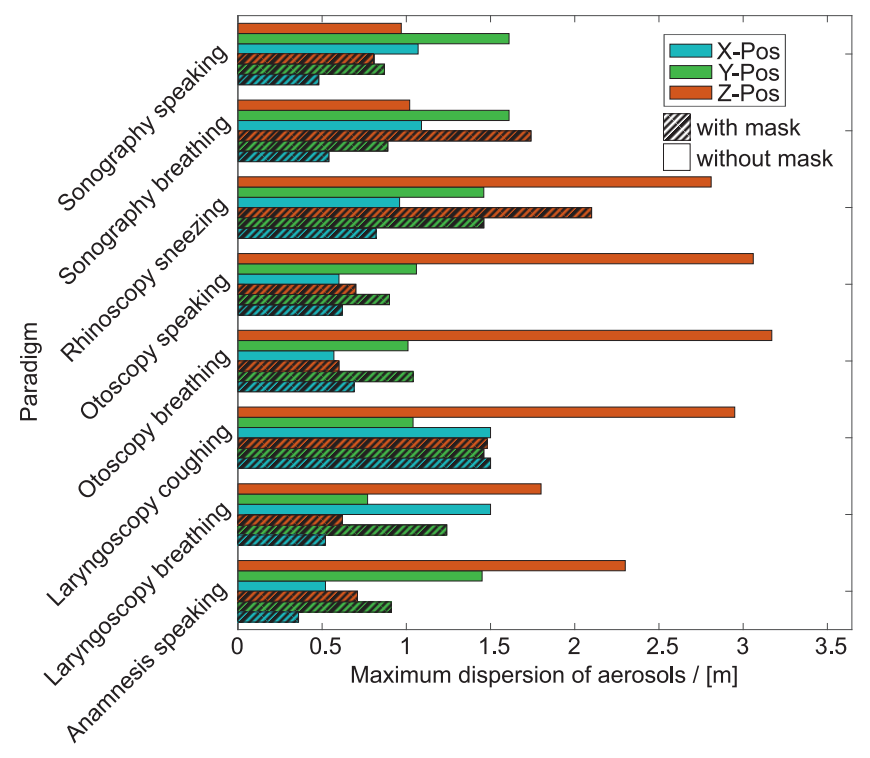

Fig. 6. Maximum dispersion (in $x-, y-$, and $z$-direction) of the aerosol particles in the numerical domain for each paradigm with and without surgical mask.

tion could be used which is already often installed in surgical rooms.

\section{Acknowledgements}

The authors acknowledge support from the Central Institute for Scientific Computing (ZISC) and computational resources and support provided by the Erlangen Regional
Computing Center (RRZE). The projected was supported by Bayerisches Wissenschaftsministeriums. 
bioRxiv preprint doi: https://doi.org/10.1101/2021.11.22.469529; this version posted November 23, 2021. The copyright holder for this preprint (which was not certified by peer review) is the author/funder. All rights reserved. No reuse allowed without permission.

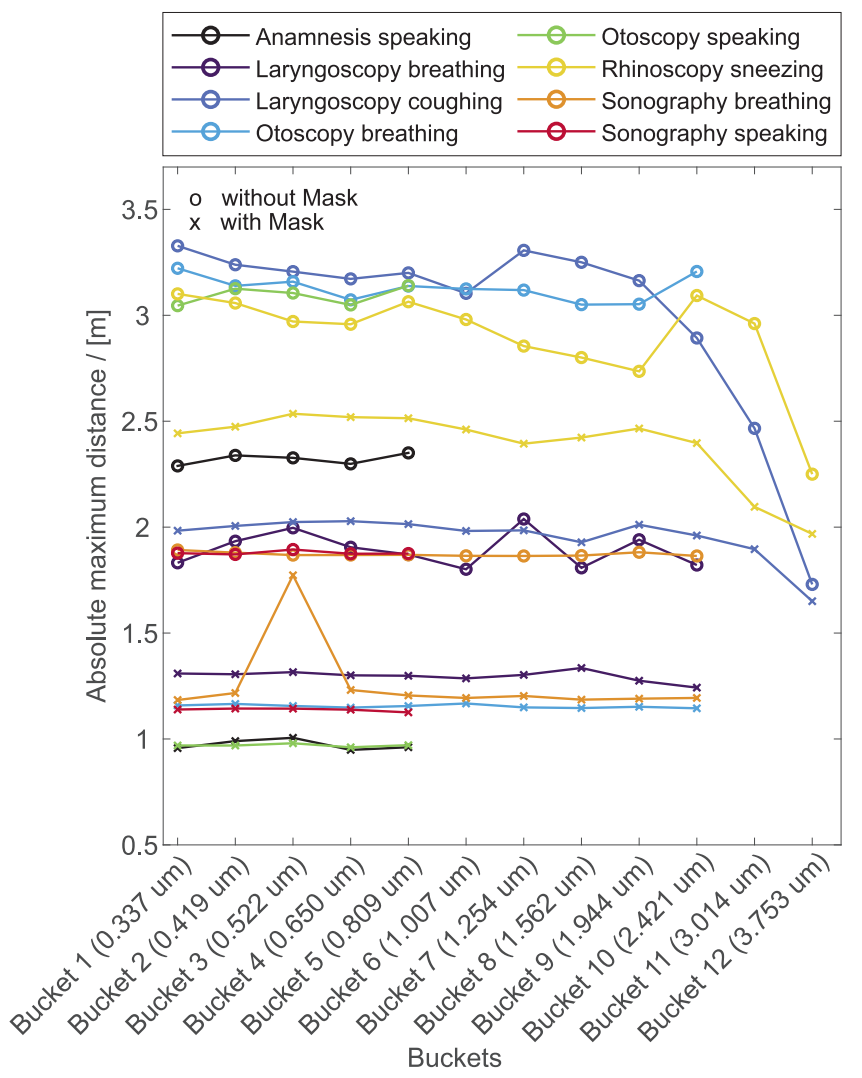

Fig. 7. Absolute maximum distance the aerosol particles travel in the numerical domain. 


\section{References}

[1] Nicola, M., Alsafi, Z., Sohrabi, C., Kerwan, A., AlJabir, A., Iosifidis, C., Agha, M., and Agha, R., 2020. "The socio-economic implications of the coronavirus pandemic (COVID-19): A review". International Journal of Surgery, 78, pp. 185-193.

[2] Lescure, F. X., Bouadma, L., Nguyen, D., Parisey, M., Wicky, P. H., Behillil, S., Gaymard, A., BouscambertDuchamp, M., Donati, F., Le Hingrat, Q., Enouf, V., Houhou-Fidouh, N., Valette, M., Mailles, A., Lucet, J. C., Mentre, F., Duval, X., Descamps, D., Malvy, D., Timsit, J. F., Lina, B., Van-der Werf, S., and Yazdanpanah, Y., 2020. "Clinical and virological data of the first cases of COVID-19 in Europe: a case series". The Lancet Infectious Diseases, 20(6), pp. 697-706.

[3] Weiss, P., and Murdoch, D. R., 2020. "Clinical course and mortality risk of severe COVID-19". The Lancet, 395(10229), pp. 1014-1015.

[4] Wölfel, R., Corman, V. M., Guggemos, W., Seilmaier, M., Zange, S., Müller, M. A., Niemeyer, D., Jones, T. C., Vollmar, P., Rothe, C., Hoelscher, M., Bleicker, T., Brünink, S., Schneider, J., Ehmann, R., Zwirglmaier, K., Drosten, C., and Wendtner, C., 2020. "Virological assessment of hospitalized patients with COVID-2019". Nature, 581(7809), pp. 465-469.

[5] Euronews, 2021. COVID-19: Estimated 115,000 healthcare workers have died from disease, says WHO - Euronews.

[6] Matava, C. T., Yu, J., and Denning, S., 2020. "Clear plastic drapes may be effective at limiting aerosolization and droplet spray during extubation: implications for COVID-19". Canadian Journal of Anesthesia/Journal canadien d'anesthésie, 67(7), pp. 902-904.

[7] Tay, J. K., Khoo, M. L.-C., and Loh, W. S., 2020. "Surgical Considerations for Tracheostomy During the COVID-19 Pandemic: Lessons Learned From the Severe Acute Respiratory Syndrome Outbreak". JAMA Otolaryngology-Head \& Neck Surgery, 146(6), pp. 517-518.

[8] Wang, J., and Du, G., 2020. “COVID-19 may transmit through aerosol". Irish Journal of Medical Science, 189(4), pp. 1143-1144.

[9] Fischer, U. "Deutsche Gesellschaft für HNOHeilkunde, Kopf-und Hals-Chirurgie (DGHNO-KHC) und ihrer Arbeitsgemeinschaft Laryngologie und Trachealerkrankungen Chirurgische Aspekte zur Tracheostomie bei Covid-19 positiven Patiente".

[10] Westhoff, M., Geiseler, J., Schönhofer, B., Pfeifer, M., Dellweg, D., Bachmann, M., and Randerath, W., 2021. "Weaning in der Situation einer Pandemie - Ein Positionspapier". Pneumologie (Stuttgart, Germany), 75(2), pp. 113-121.

[11] Kluge, S., Janssens, U., Welte, T., Weber-Carstens, S., Schälte, G., Spinner, C. D., Malin, J. J., Gastmeier, P., Langer, F., Wepler, M., Westhoff, M., Pfeifer, M., Rabe, K. F., Hoffmann, F., Böttiger, B. W., WeinmannMenke, J., Kersten, A., Berlit, P., Haase, R., Marx, G., and Karagiannidis, C., 2020. "S2k-Leitlinie-
Empfehlungen zur stationären Therapie von Patienten mit COVID-19". Pneumologie (Stuttgart, Germany), 75(2), pp. 88-112.

[12] Sosnowski, T. R., 2021. "Inhaled aerosols: their role in COVID-19 transmission including biophysical interactions in the lungs". Current Opinion in Colloid \& Interface Science, 54, p. 101451.

[13] Nielsen, P., and Liu, L., 2020. The influence of air distribution on droplet infection and airborne cross infection. Tech. rep.

[14] World Health Organization, 2020. Modes of transmission of virus causing COVID-19: implications for IPC precaution recommendations: scientific brief, 29 March 2020.

[15] Mueller, S., Veltrup, R., Jakubaß, B., Kniesburges, S., Huebner, M., Kempfle, J., Dittrich, S., Iro, H., and Döllinger, M., 2021. "Clinical characterization of respiratory droplet production during common airway procedures using high-speed imaging". Scientific Reports, 11(1), p. 10627.

[16] Li, Q., Guan, X., Wu, P., Wang, X., Zhou, L., Tong, Y., Ren, R., Leung, K. S., Lau, E. H., Wong, J. Y., Xing, X., Xiang, N., Wu, Y., Li, C., Chen, Q., Li, D., Liu, T., Zhao, J., Liu, M., Tu, W., Chen, C., Jin, L., Yang, R., Wang, Q., Zhou, S., Wang, R., Liu, H., Luo, Y., Liu, Y., Shao, G., Li, H., Tao, Z., Yang, Y., Deng, Z., Liu, B., Ma, Z., Zhang, Y., Shi, G., Lam, T. T., Wu, J. T., Gao, G. F., Cowling, B. J., Yang, B., Leung, G. M., and Feng, Z., 2020. "Early Transmission Dynamics in Wuhan, China, of Novel Coronavirus-Infected Pneumonia". New England Journal of Medicine, 382(13), pp. 1199-1207.

[17] van Doremalen, N., Bushmaker, T., Morris, D. H., Holbrook, M. G., Gamble, A., Williamson, B. N., Tamin, A., Harcourt, J. L., Thornburg, N. J., Gerber, S. I., Lloyd-Smith, J. O., de Wit, E., and Munster, V. J., 2020. "Aerosol and Surface Stability of SARS-CoV2 as Compared with SARS-CoV-1". The New England journal of medicine, 382(16), pp. 1564-1567.

[18] Edwards, D. A., Man, J. C., Brand, P., Katstra, J. P., Sommerer, K., Stone, H. A., Warded, E., and Scheuch, G., 2004. "Inhaling to mitigate exhaled bioaerosols". Proceedings of the National Academy of Sciences, 101(50), pp. 17383-17388.

[19] Hersen, G., Moularat, S., Robine, E., Géhin, E., Corbet, S., Vabret, A., and Freymuth, F., 2008. "Impact of Health on Particle Size of Exhaled Respiratory Aerosols: Case-control Study". CLEAN - Soil, Air, Water, 36(7), pp. 572-577.

[20] Scheuch, G., 2020. "Breathing Is Enough: For the Spread of Influenza Virus and SARS-CoV-2 by Breathing Only". Journal of aerosol medicine and pulmonary drug delivery, 33(4), pp. 230-234.

[21] Edwards, D. A., Ausiello, D., Salzman, J., Devlin, T., Langer, R., Beddingfield, B. J., Fears, A. C., DoyleMeyers, L. A., Redmann, R. K., Killeen, S. Z., Maness, N. J., and Roy, C. J., 2021. "Exhaled aerosol increases with COVID-19 infection, age, and obesity". Pro- 
ceedings of the National Academy of Sciences, 118(8), p. e2021830118.

[22] Dudalski, N., Mohamed, A., Mubareka, S., Bi, R., Zhang, C., and Savory, E., 2020. "Experimental investigation of far-field human cough airflows from healthy and influenza-infected subjects". Indoor Air, 30(5), pp. 966-977.

[23] Anfinrud, P., Stadnytskyi, V., Bax, C. E., and Bax, A., 2020. "Visualizing Speech-Generated Oral Fluid Droplets with Laser Light Scattering". The New England journal of medicine, 382(21), pp. 2061-2063.

[24] Dbouk, T., and Drikakis, D., 2020. "On coughing and airborne droplet transmission to humans". Physics of Fluids, 32(5), p. 053310.

[25] Leonard, S., Strasser, W., Whittle, J. S., Volakis, L. I., DeBellis, R. J., Prichard, R., Atwood, C. W., and Dungan, G. C., 2020. "Reducing aerosol dispersion by high flow therapy in COVID-19: High resolution computational fluid dynamics simulations of particle behavior during high velocity nasal insufflation with a simple surgical mask". Journal of the American College of Emergency Physicians Open, 1(4), pp. 578-591.

[26] Bhattacharyya, S., Dey, K., Paul, A. R., and Biswas, R., 2020. "A novel CFD analysis to minimize the spread of COVID-19 virus in hospital isolation room". Chaos, Solitons \& Fractals, 139, p. 110294.

[27] Przekwas, A., and Chen, Z., 2020. "Washing hands and the face may reduce COVID-19 infection". Medical Hypotheses, 144, p. 110261.

[28] Peng, S., Chen, Q., and Liu, E., 2020. "The role of computational fluid dynamics tools on investigation of pathogen transmission: Prevention and control". Science of The Total Environment, 746, p. 142090.

[29] Ren, J., Wang, Y., Liu, Q., and Liu, Y., 2021. "Numerical Study of Three Ventilation Strategies in a prefabricated COVID-19 inpatient ward". Building and Environment, 188, p. 107467.

[30] ERCOFTAC, 2021. ERCOFTAC CADO - "How much do we know and how much we don't know about the Covid 19 Flow Physics".

[31] ERCOFTAC, 2021. ERCOFTAC CADO - The Second Zoom Meeting on Covid 19 Flows: Study and Practical Recommendations.

[32] Shao, S., Zhou, D., He, R., Li, J., Zou, S., Mallery, K., Kumar, S., Yang, S., and Hong, J., 2021. "Risk assessment of airborne transmission of COVID-19 by asymptomatic individuals under different practical settings". Journal of Aerosol Science, 151, p. 105661.

[33] Kähler, C. J., and Hain, R., 2020. "Fundamental protective mechanisms of face masks against droplet infections". Journal of aerosol science, 148, p. 105617.

[34] Pendar, M. R., and Páscoa, J. C., 2020. "Numerical modeling of the distribution of virus carrying saliva droplets during sneeze and cough". Physics of Fluids, 32(8), p. 083305.

[35] Digital Industries Software, S., 2020. Simcenter StarCCM+ User Guide v. 2020.2. Tech. rep.

[36] Papoulias, D., and Lo, S., 2015. "Advances in CFD modelling of multiphase flows in cyclone separators". Chemical Engineering Transactions, 43, pp. 16031608.

[37] Crowe, C. T., Sommerfeld, M., and Tsuji, Y., 1998. Multiphase Flows with Droplets and Particles. CRC Press.

[38] Hamdi, M., Havet, M., Rouaud, O., and Tarlet, D., 2014. "Comparison of different tracers for PIV measurements in EHD airflow". Experiments in Fluids, 55(4), pp. 1-12.

[39] Menter, F. R., 1994. "Two-equation eddy-viscosity turbulence models for engineering applications". AIAA Journal, 32(8), pp. 1598-1605.

[40] Peters, G., Wendler, O., Böhringer, D., Gostian, A.O., Müller, S. K., Canziani, H., Hesse, N., Semmler, M., Berry, D. A., Kniesburges, S., Peukert, W., and Döllinger, M., 2021. "Human Laryngeal Mucus from the Vocal Folds: Rheological Characterization by Particle Tracking Microrheology and Oscillatory Shear Rheology”. Applied Sciences, 11(7), p. 3011.

[41] Breuer, M., 2002. Direkte Numerische Simulation und Large-Eddy Simulation turbulenter Strömungen auf Hochleistungsrechnern. Shaker Verlag, Aachen.

[42] Bae, S., Kim, S. H., and Lee, J. H., 2020. "An investigation into the hydrodynamics of a spinning cone column: CFD simulations by an Eulerian-Lagrangian approach". Computers \& Chemical Engineering, 132, p. 106635.

[43] Zörner, S., Kaltenbacher, M., and Döllinger, M., 2013. "Investigation of prescribed movement in fluid-structure interaction simulation for the human phonation process". Computers and Fluids, 86(100), pp. 133-140.

[44] Sadeghi, H., Döllinger, M., Kaltenbacher, M., and Kniesburges, S., 2019. "Aerodynamic impact of the ventricular folds in computational larynx models". The Journal of the Acoustical Society of America, 145(4), p. 2376.

[45] Wei, J., and Li, Y., 2017. "Human Cough as a TwoStage Jet and Its Role in Particle Transport". PLOS ONE, 12(1), p. e0169235.

[46] Gupta, J. K., Lin, C. H., and Chen, Q., 2009. "Flow dynamics and characterization of a cough". Indoor Air, 19(6), pp. 517-525.

[47] Tabuenca, J. G., 2021. tidal_breathing_segmentation (https://github.com/javier-graciatabuenca/tidal_breathing_segmentation, GitHub.).

[48] van Hattum, R. J., and Worth, J. H., 1967. "Air Flow Rates in Normal Speakers". The Cleft Palate Journal, 4(2), pp. 137-147.

[49] Asadi, S., Wexler, A. S., Cappa, C. D., Barreda, S., Bouvier, N. M., and Ristenpart, W. D., 2019. “Aerosol emission and superemission during human speech increase with voice loudness". Scientific Reports, 9(1), p. 2348.

[50] Verma, S., Dhanak, M., and Frankenfield, J., 2020. "Visualizing the effectiveness of face masks in obstructing respiratory jets". Physics of Fluids, 32(6), p. 061708. 
[51] Ishii, K., Ohno, Y., Oikawa, M., and Onishi, N., 2021. "Relationship between human exhalation diffusion and posture in face-to-face scenario with utterance". Physics of Fluids, 33(2), p. 027101.

[52] Kniesburges, S., Schlegel, P., Peters, G., Westphalen, C., Jakubaß, B., Veltrup, R., Kist, A. M., Döllinger, M., Gantner, S., Kuranova, L., Benthaus, T., Semmler, M., and Echternach, M., 2021. "Effects of surgical masks on aerosol dispersion in professional singing". Journal of Exposure Science \& Environmental Epidemiology 2021, pp. 1-8. 